\title{
The Large-Scale Spatial Patterns of Ecological Networks Between Phytoplankton and Zooplankton in Coastal Marine Ecosystems
}

\section{Zheng Zhang}

Shandong University

Hongjun Li

National Marine Environmental Monitoring Center

\section{Wenli Shen}

Shandong University

\section{Xiongfeng Du}

Research Centre for Eco-Environmental Sciences Chinese Academy of Sciences

\section{Shuzhen Li}

Daliang University of Technology

\section{Ziyan Wei}

Institute of Microbiology, Chinese Academy of Sciences

\section{Kai Feng}

Research Center for Eco-Environmental Sciences, Chinese Academy of Sciences

Ye Deng ( $\nabla$ yedeng@rcees.ac.cn )

Chinese Academy of Sciences https://orcid.org/0000-0002-7584-0632

\section{Research}

Keywords: Large scale, Plankton, Biogeography, Bipartite network, Distance decay, Planktonic interaction

Posted Date: November 13th, 2020

DOI: https://doi.org/10.21203/rs.3.rs-104574/v1

License: (1) (1) This work is licensed under a Creative Commons Attribution 4.0 International License.

Read Full License

Version of Record: A version of this preprint was published at Science of The Total Environment on March 1st, 2022. See the published version at https://doi.org/10.1016/j.scitotenv.2022.154285. 


\section{Abstract}

\section{Background}

The marine autotrophic phytoplankton is responsible for approximately half of global primary production on Earth, and as the planktonic consumers, the heterotrophic zooplankton could link the phytoplankton and higher trophic level to complete the aquatic Food Web. Despite the interaction between phytoplankton and zooplankton has played important roles in speciation and ecosystem function, little is known about the spatial patterns of their interactions at the continental scale.

Results

Here, we collected 251 seawater samples along 13,000 km of Chinese coastline, and microscopically investigated the spatial gradient patterns of phytoplanktonic and zooplanktonic diversities. In total, 307 phytoplanktonic and 311 zooplanktonic species were visually identified. The distance-decay relationships showed higher turnover rates for zooplankton than phytoplankton, indicating zooplankton had more divergent compositions across larger distances. Furthermore, the zooplankton-phytoplankton interaction networks demonstrated more complex and numerous connections along the southern coast than in the north, suggesting the interactions between these two major planktonic groups had a geographic spatial pattern. The types of planktonic interactions changed along the latitudinal gradient, with positive interactions dominant in northern and middle regions, while the percentage of positive and negative interactions were approximately equal in the southern latitudinal region. Additionally, some particular association between zooplanktonic and phytoplanktonic groups were found to be localized in specific regions, such as autotrophic $C$. lorenzianus was only associated with heterotrophic Copepoda in northern region, and $C$. oculus-iridis was only associated with Copepoda and Chaetognatha in the middle (ECS) and southern (SCS) respectively.

\section{Conclusions}

We demonstrate here that not only the planktonic biodiversity and community structure exhibited a clear spatial pattern, but also the interaction between phytoplankton and zooplankton also changed with spatial variation. Our results provide a valuable ecological perspective to the biogeography patterns of coastal plankton along the large-scale spatial gradients, and have important implications for understanding how complex planktonic species interactions changed with location variation.

\section{Background}

According to trophic strategy, grouping organisms that interact with environmental factors in similar ways, the marine planktonic protists has been classified into two major groups: photosynthetic phytoplankton and heterotrophic zooplankton [1, 2]. As the primary producers in the pelagic food web, marine phytoplankton accounts for almost $50 \%$ of global primary production, meanwhile zooplankton acts as the important linker between primary producers and oceanic macrofauna [3]. The relationship 
between zooplankton and phytoplankton is the foundation of the aquatic food web, and changes within marine plankton communities would also impact global biogeochemical cycles. Most phytoplankton and zooplankton species are sensitive to changes in the marine environment and their responses may directly influence oceanic ecosystem functions [4, 5]. For example, rising temperature can reduce phytoplankton relative cell-size [6] and increased salinity will dramatically reduce the planktonic richness [7]. Phytoplankton organisms are able to fix atmospheric $\mathrm{CO}_{2}$ by photosynthesis which might promote the oceanic carbon cycle [8]. The plankton study by Falkowski and Oliver [9] was largely focused on the effects of global climate change on phytoplankton community structure, however, there was a clear knowledge gap about the interactions between phytoplankton and zooplankton over geographic distances and variations in environment factors [10].

As one of the fundamental patterns in understanding the structure of the biosphere, spatial patterns of species diversity offer insights to predict the mechanisms shaping community structure $[11,12]$. The spatial distribution of phytoplanktonic and zooplanktonic species could reveal their adaptations to many different environmental properties. Due to variations of plankton richness and community structure in space reflecting the multiple mechanisms of species loss and maintenance, the biogeography of plankton has become one of the central concerns in marine ecology [13]. The distance-decay relationship (DDR) can exam spatial changes in biodiversity and describe the dissimilarity of taxonomic composition with increasing geographic distances [14]. Dumbrell et al. [15] and Chase [16] have compared the relative influence of different assembly processes in species turnover rate (the slope in DDR) and indicated that community assemble processes strongly influence organism distribution and community structure. Despite these initial studies, little is known about its association with the phytoplankton and zooplankton communities in large-scale marine ecosystems.

The interaction of planktonic species play a crucial role in both species evolution and the maintenance of ecosystem functions [12], but these comprehensive interactions become too complex at the community level to be observed directly. Bjorbaekmo et al. generated a publicly available Protist Interaction Database (PIDA), which grouped protist interactions into four types: parasitism, predation, symbiosis, and 'unresolvedinteraction' [12]. In the marine ecosystem, phytoplankton and zooplankton form a complicated interaction network through those four types of interaction, but the relationship between plankton interaction and spatial change is still poorly understood [17]. Network-based inference approaches are frequently used to disentangle complex interactions among microbial species, by identifying those interactions through co-occurrence patterns across a series of spatial or temporal samples [18-20]. The topologies of an ecological network can characterize the assembly process of a microbial community [21], and the links among interacting species can provide predictions on the stability of ecosystems [22]. Recently, Feng et al. constructed a workflow of interdomain ecological network (IDEN) analysis which could infer the associations between two taxonomic groups (i.e. aboveground plants vs. belowground bacteria) in ecological surveys [23]. The network topological structure properties (e.g., total links, connectance, web asymmetry, and nestedness) from IDEN analysis results could be used to evaluate the complexity of the phytoplankton-zooplankton networks [23]. Additionally, the most important nodes or 
hubs in this network, which might be the most influential members in the microbial community, could be identified through topological modular analysis [24].

In this study, we analyzed 251 samples from the surface ocean at 12 sites encompassing the coastal area of China and investigated how environmental factors drive changes in the planktonic community. Our goal was to address the geographic pattern of interactions between phytoplankton and zooplankton. Therefore, we hypothesized that (i) both coastal zooplanktonic and phytoplanktonic communities have a clear latitudinal distribution pattern and different turnover rates with spatial scaling; and (ii) the interaction networks between zooplankton and phytoplankton would vary along a latitudinal gradient, and that preferential associations existed between specific zooplankton and phytoplankton species.

\section{Results}

\section{Diversities of the phytoplanktonic and zooplanktonic communities}

A total of 251 waters samples were collected from 12 sites along the coast of China, covering more than 13,000 km (Fig. S1). 12 water chemical variables were measured for each sample (i.e. pH, salinity, COD, $\mathrm{DO}, \mathrm{Pb}^{2+}, \mathrm{Cu}^{2+}, \mathrm{Zn}^{2+}, \mathrm{As}^{3+}, \mathrm{NO}_{2}-\mathrm{N}, \mathrm{NO}_{3}-\mathrm{N}, \mathrm{NH}_{4}-\mathrm{N}$ and Chlorophyll-a concentration) (Table S1). The samples could be grouped into three geographic regions, Bohai Sea (BS), East China Sea (ECS), and South China Sea (SCS), representing the northern, middle, and southern regions of the Chinese coastal marine ecosystems respectively.

A total 307 phytoplanktonic species and 311 zooplanktonic species were identified, and the total planktonic density counted in each sample. The relative abundance of plankton species in all sampling sites are summarized at the genus level (Fig. 1). The Paracalanus was the dominant zooplanktonic genus in most sampling sites, except Site2 and Site8. In those two stations, Acartia and Amphorellopsis have the highest relative abundance, respectively (Fig. 1A). In the phytoplankton, the Skelectonema was the major genus in most sites. But the Chactoceros was the dominant genus in Site5 and Site6, and the Coscinodiscus has a higher relative abundance than others in the Site9 (Fig. 1B). The northern region has the highest total zooplanktonic density, and then rapid decline along with the latitude decrease (Fig. 1A). The phytoplankton has opposite tendencies, the southern region has a higher total density than the middle and northern regions (Fig. 1B). The observed richness of phytoplankton and zooplankton both showed significant geographic differences among all sampling sites (Fig. S2A and S2D, Table S2, Kruskal-Wallis test, $P<0.05)$. More precisely, we found they had the lowest richness in the northernmost site 1 and then richness, in general, gradually increased as latitude decreased, though the maximum richness did not appear in the southernmost site, Site 12 (Fig. S2A and S2D). By grouping the closest sites into three regions (BS, ECS, and SCS), this trend became much clearer (Fig. S2B and S2E; KruskalWallis test, $P<0.001$ ) with both phytoplanktonic and zooplanktonic richness showing significant linear correlation to latitude (Fig. S2C and S2F; $P<0.001$ ). Together, these results indicated there were significant latitudinal gradients in the richness of both zooplankton and phytoplankton. 


\section{Phytoplankton and zooplankton exhibiting distinct features}

Coastal ecosystem zooplankton and phytoplankton community relationships were visualized via nonmetric multidimensional scaling (NMDS) of the compositional dissimilarities, showed that both the zooplanktonic and phytoplanktonic communities of the 12 sites formed distinct clusters as confirmed by similarity analysis (ANOSIM, permutations $=999, p=0.001$ ), permutational multivariate analysis of variance (ADONIS, permutations $=999, p=0.001$ ), and multi response permutation procedure (MRPP, permutations $=999, p=0.001$ ) (Fig. 2). Together these results indicated that the species composition of both the phytoplanktonic and zooplanktonic communities was significantly different among the 12 sampling sites.

To reveal the biogeographic patterns of both phytoplanktonic and zooplanktonic communities and the drivers of plankton beta diversity, we measured the distance-decay relationships (DDRs) between beta diversity (Sorensen) and geographic distances (Fig. S3). The slopes of both DDRs reflected the spatial turnover rates at which planktonic dissimilarity significantly increased with geographic distance $(P=0.01)$. Permutation test showed that the spatial turnover rate (the slope) of the zooplanktonic community (0.074) was significantly steeper $(P<0.001)$ than the phytoplanktonic community $(0.047)$, suggesting the zooplanktonic community had greater differences than phytoplankton across larger spatial scales.

\section{Environmental factors on shaping these two planktonic communities}

To identify which environmental factor(s) and/or if geographic distance played more important role(s) in driving phytoplanktonic and zooplanktonic communities, partial Mantel tests (Spearman's correlation, permutations $=999$ ) were implemented (Table 1). Geographic distance showed a significant contribution to both zooplanktonic $(r=0.23, P=0.001)$ and phytoplanktonic $(r=0.24, P=0.001)$ communities. Compared to the phytoplanktonic community $(r=0.30, P=0.001)$, the joint environmental factors showed greater contribution to the zooplanktonic community $(r=0.49, P=0.001)$. Canonical Correlation Analysis (CCA) was used to identify the environmental and spatial variations in shaping the phytoplanktonic and zooplanktonic community structures (Fig. S4). Total 16 spatial factors (PCNM1-16) were generated to explore the contribution of spatial in constructing the planktonic communities. 10 spatial and 9 environmental factors were contributed significantly to explaining the zooplanktonic community composition. For the phytoplanktonic community, the significant factors consisted of 5 spatial and 7 environmental factors (Table S3). The results of variation partitioning analysis (VPA) revealed that the spatial variables contributed a substantially larger proportion of variation relative to environmental factors to the zooplankton (16.463\%) and phytoplankton (9.279\%) community, suggesting spatial limitation could be an important factor determining the compositions of both phytoplankton and zooplankton in this latitudinal gradient.

Table 1. Partial Mantel tests showing the correlations between planktonic community compositions and environmental distance or geographic distance. 


\begin{tabular}{|c|c|c|c|c|c|}
\hline & \multirow[t]{2}{*}{ Partial } & \multicolumn{2}{|c|}{ Zooplankton } & \multicolumn{2}{|c|}{ Phytoplankton } \\
\hline & & $r_{M}$ & $P$ & $r_{M}$ & $P$ \\
\hline $\begin{array}{l}\text { Geographic } \\
\text { distance }\end{array}$ & $\begin{array}{l}\text { Environmental } \\
\text { factors }\end{array}$ & 0.23 & 0.001 & 0.24 & 0.001 \\
\hline $\begin{array}{l}\text { Environmental } \\
\text { factors }\end{array}$ & $\begin{array}{l}\text { Geographic } \\
\text { distance }\end{array}$ & 0.49 & 0.001 & 0.30 & 0.001 \\
\hline
\end{tabular}

\section{Interaction network between two planktonic communities}

The Inter-Domain Ecological Network (IDEN) approach [23] was implemented to analyze the interaction between phytoplanktonic and zooplanktonic species in the three regions. These three bipartite networks were obvious topological differences (Fig. 3). The structure of the southern region (SCS) phytoplanktonzooplankton network (Fig. 3C) showed higher complexity and connectivity than those of other two regions (BS and ECS) (Fig. 3A and 3B). According the topological indexes of these bipartite networks (Table 2), the network size (number of nodes), number of links, and connectance all demonstrated that the interactions between phytoplanktonic and zooplanktonic species became closer from north to south. This suggested that the interactions between phytoplankton and zooplankton also had a latitudinal gradient along the Chinese coastline.

Table 2. Network topological structure properties for the planktonic bipartite networks of the three regions. (BS) Bohai Sea, (ECS) East China Sea, (SCS) South China Sea. 


\begin{tabular}{|llll|}
\hline & BS & ECS & SCS \\
\hline No.phy & 66 & 87 & 63 \\
\hline No.zoo & 39 & 68 & 42 \\
\hline Total link & 254 & 587 & 1294 \\
\hline Positive Link & 186 & 444 & 711 \\
\hline Negative Link & 68 & 143 & 583 \\
\hline Connectance & 0.0987 & 0.0992 & 0.1015 \\
\hline Web asymmetry & 0.2571 & 0.1226 & 0.1013 \\
\hline Links per species & 2.4190 & 3.7871 & 5.7004 \\
\hline No.of compartments & 2 & 4 & 4 \\
\hline Specialization & -0.1204 & -0.701 & -0.0626 \\
\hline asymmetry & & & \\
\hline Modularity & 0.5356 & 0.4709 & 0.3313 \\
\hline No. of modules & 6 & 10 & 11 \\
\hline
\end{tabular}

In order to distinguish the most important species, the networks were further classified into substructures, called modules, which contained groups of species that have intensive interactions with each other, but few interactions with members from other modules. The topological role of each node (species) could be measured by using its within-module connectivity $\left(Z_{i}\right)$ and among-module connectivity $\left(P_{i}\right)$. All planktonic species in the $Z_{i} P_{i}$ plot could be divided into four categories: peripherals, connectors, module hubs, and network hubs. The latter three were considered as keystone taxa in the bipartite networks (Fig S5). The phytoplankton-zooplankton networks were primarily composed of keystone taxa and their neighbor (Fig. 3D-F). Subnetworks for the interactions among keystone taxa and their neighbors were analyzed to identify the role of these members in structuring the planktonic communities. These subnetworks contained the majority of planktonic organisms and had the same structure variation patterns as the full networks, in being more complex and tighter in the middle and southern regions (ECS and SCS) than the northern region (BS).

The specific interactions between common important phytoplanktonic and zooplanktonic species in the bipartite networks were studied further detail. First, the subnetworks for the interactions among three predominant planktonic group, (diatoms, copepoda, and dinoflagellates), were analyzed to reveal how the relationships between them changed along the latitudinal gradient (Fig. $3 \mathrm{G}-\mathrm{I}$ ). The maximum proportion of diatoms was found in the northern region (BS, 62.5\%), and then gradually decreased with decreasing latitude (55.17\% for ECS and $54.48 \%$ for SCS). The proportion of dinoflagellates ( $10.42 \%$ for ES, $12.65 \%$ for ECS, and $13.80 \%$ for SCS) in the subnetworks, showed an increasing trend from north to south. In 
addition, a lower percentage of copepoda was observed in the BS $(27.08 \%)$ than in ECS $(32.18 \%)$ or SCS (31.72\%) (Fig. 3G-I). We found the percentage of interaction types (positive and negative relationships) also changed with latitude. Positive relationships made up the majority of planktonic interactions (68.04\%) in the middle region (ECS), and then decreased towards the south (SCS, 52.43\%) and north (BS, $60.94 \%$ ) regions. In addition, 17 planktonic species (10 phytoplanktonic species and 7 zooplanktonic species) were found in all three planktonic networks, and those organisms were linked with different neighbors in three regions. However, none of the planktonic links appeared two or more times in the three regions, indicating that the relationship between zooplankton and phytoplankton was altered between geographic regions, and that planktonic species link with different neighbors when they appeared in different the locations.

Based on the above bipartite network, we extracted a subnetwork which only contained the common planktonic species observed in all three sampling regions with their neighbors (Fig. 4). Most of these common planktonic species (8 phytoplankton and 5 zooplankton) had almost equivalent neighbors in all three regions (the spots in the middle of Fig. 4). However, the phytoplanktonic Coscinodiscus oculus-iridis and zooplanktonic Centropages orsinii were both associated with more neighbors in northern (BS) region than the other two regions, while phytoplanktonic Chaetocero lorenzianus and zooplanktonic Oncaea clevei had more and more neighbors from north to south. Although the majority of planktonic species were associated with consistent planktonic neighbors in three regions, some interactions have been altered among regions. For example, $C$. Iorenzianus showed interactions with Planktonic larvae in both middle (ECS) and southern (SCS), but only associated with Copepoda in northern (BS). The phytoplanktonic $C$. oculus-iridis has a specific relationship in different regions, it was only associated with Copepoda and Chaetognatha in the middle (ECS) and southern (SCS) respectively. These results demonstrated the interactions between phytoplankton and zooplankton had a clear spatial pattern while different planktonic species could contact with specific taxa in different regions.

\section{Discussion}

Coastal marine ecosystems are among the most ecologically and socio-economically vital zones on the planet [25], and there are increasing concerns regarding the impacts of anthropogenic pollution and climate change. Previous studies have suggested that many planktonic species are sensitive to even slight climatic change [26]. Though researchers have long recognized that planktonic interactions are crucial for oceanic and coastal ecosystems, our knowledge about how they change over geographic distance is still lacking $[27,28]$. In this study, we performed a large-scale systematic survey of both phytoplankton and zooplankton in 251 seawater samples along 13,000 km of coastline (Fig. S1), we aimed to reveal the spatial patterns for both phytoplanktonic and zooplanktonic community composition, geographic distribution, and their interactions.

\section{Coastal zooplanktonic and phytoplanktonic communities exhibited distinct latitudinal distribution patterns}


Consistent with our first hypothesis, both zooplanktonic and phytoplanktonic communities exhibited a clear geographic pattern (Fig. 2). Although the dominant genus was changed in different sampling sites and the biomass did not always have the same variation trend, our results showed that the diversity of zooplankton and phytoplankton both increased with decreasing latitude according to the observed richness indices (Fig. S2).

The zooplankton and phytoplankton of the middle and southern regions (ECS and SCS) showed significantly higher richness than the northern region (BS), indicating more planktonic species existed in warmer coastal marine ecosystems than in colder areas. This was consistent with previous study which found that plankton displays a significant latitudinal gradient [29-31]. Many environmental factors could shape this latitudinal gradient distribution, including temperature, salinity and nutrient availability [32, 33]. In our study, the CCA model analysis suggested that both geographic distance and environmental factors had great influence on both the zooplanktonic and phytoplanktonic communities (Fig. S4A and S4C). Some previous studies have provided evidence that the microbial eukaryotic community can be impacted by environmental factors, such as $\mathrm{DO}, \mathrm{COD}$ [34], nutrient concentration $\left(\mathrm{NO}_{3}-\mathrm{N}\right.$ and $\left.\mathrm{NH}_{4}-\mathrm{N}\right)$ [35] and salinity [36], which was consistent with our finding along Chinese coastline. One recent study found that environmental parameters were more important in driving zooplanktonic diversity than geographic distance [37]. Inconsistent with this conclusion, that environmental filtering shaped phytoplanktonic community's composition, we found the diversities of both zooplankton and phytoplankton were more impacted by geographic distance than environmental variables (Fig. S4B and S4D). Overall, our results provided evidence to support that oceanic zooplanktonic and phytoplanktonic communities exhibit biogeographical patterns at large scale, was and that these patterns are mainly shaped by both geographic distance and environmental factors.

The spatial turnover rate reflects a combination of species dispersal limitation and environmental changes [38, 39], which could be critical to understanding planktonic ecology and evolution. The distance-decay relationship is a classic concept of biogeography that can [38] and the increasing community dissimilarity with increasing geographic distance. And the slope of the distance-decay relationship could reflect the varying rates of species turnover. Although it is difficult to quantify all environmental variables [40], we found purely spatial variables have greater contributions than the measured environmental factors in constructing both the phytoplanktonic and zooplanktonic communities. Nekola et al. reported that the difference in plant ecological communities increased with distance [41]. This is consistent with our study, where we observed a significant positive relationship between the $\beta$-diversity of both planktonic communities and geographic distance. In our study, distinct distance-decay relationships were established for both zooplanktonic and phytoplanktonic communities in coastal ecosystems across $13,000 \mathrm{~km}$ Chinese coastline. The slope of zooplanktonic (0.074) distancedecay relationship was steeper than phytoplanktonic (0.047), that indicating the phytoplankton and zooplankton have different spatial turnover rates and a greater number of different zooplanktonic species appeared over large distances than in the phytoplankton community (Fig. S3). It also could imply that zooplanktonic species had narrower geographic distributions than phytoplanktonic species. The above 
results are consistent with our first hypothesis that both zooplankton and phytoplankton communities have a significant latitude distribution pattern and different turnover rates with spatial scaling.

\section{The interaction networks between zooplankton and phytoplankton also exhibited spatial divergences}

The interactions between zooplankton and phytoplankton are an important part of the oceanic food web [42], and can be shaped by a wide range of biotic and abiotic factors [43]. Network inference approaches have been used to elucidate the complex species interactions within microbial community in various ecosystems [44-46]. In this study, we applied the newly developed IDEN approach to investigate the bipartite ecological networks between phytoplankton and zooplankton and revealed their topological features along a latitudinal gradient [23]. According to the network analysis, there was a clear spatial pattern of interaction networks in that the planktonic community exhibited more complex associations at low-latitudinal regions than high-latitudinal (Fig. 3). This could be explained by the higher ocean surface temperatures driving increased ocean stratification, which triggers an accumulation of phytoplankton and stimulates zooplankton consumption and growth [47-49]. Therefore, our results suggested that a more diverse phytoplanktonic community in warmer coastal marine waters could increase the diversity of the zooplanktonic community through more complex trophic associations.

Through the construction of subnetworks, highlighting specific types of planktonic organisms (copepods, diatoms, and dinoflagellates), we found that these also exhibited specific geographic patterns (Fig. 3). Diatoms and dinoflagellate are played key roles in fixating a large fraction of $\mathrm{CO}_{2}$ in the surface ocean [50]. As Malviya et al. stated in their study, that diatoms were widely distributed at high latitudes and considered to be important in these colder regions [51]. While Rombouts et al. found copepods, as a key trophic link between phytoplankton and fish have the highest diversity in the subtropics of the Northern Hemisphere [52]. Not only were our results consistent with the above studies, but we also found the interaction between dominant phytoplanktonic and zooplanktonic organism types also exhibited latitudinal patterns (Fig. 3). PIDA documents the pairwise interactions between aquatic protists, and this data can be compared with our bipartite interaction network to further investigate our hypotheses about planktonic interactions. According to PIDA, predation (39\%) and parasitism (18\%) were the most commonly investigated based on direct observation [12], but we found that positive relationships dominated in most regions, except in the low-latitude region (SCS), where the proportion of positive and negative interaction were almost equal. One possible explanation is that rising temperature could elevate the taxon niche widths and increase metabolic rates [53], causing zooplanktonic and phytoplanktonic species to face greater competitive pressure in regions with limited resources.

The subnetworks for the planktonic species shared by sampling region also demonstrated clear latitudinal variation patterns similar to the pattern of their respective whole networks (Fig. 4). Part of this pattern was that with decreasing latitude both 0. clevei and C.lorenzianus displayed a greater number of interactions with other organisms. C.lorenzianus as one of the largest diatoms, is common in coastal waters throughout the global tropical and temperate regions [54]. The dominant phytoplanktonic specie often form blooms, sometimes with negative impact on coastal ecosystems and fish farms $[55,56]$. Our

Page $10 / 25$ 
results showed copepods were the major neighbors associated with C.lorenzianus in the sampling regions. This is likely due to copepods, as the energy transfer bridge from phytoplankton to fish, usually dominate the zooplankton in diatom and dinoflagellate spring bloom regions [57], and Koski et al. indicated that the dominant Copepoda, Oncaea spp., was able to feed only when the food was in the form of aggregates [58]. The changing relationship between planktonic taxa and O.clevei and C.lorenzianus with geographic variation might be explained by changes in habitat affecting basic biology and ecological functions, which further impacted planktonic roles in the coastal ecosystem [59].

Interestingly, not all planktonic organism relationships showed the same latitudinal pattern as above. A previous study demonstrated that the genus Centropages was likely to be favored under post-spring bloom conditions to avoid competition with other copepods [60]. Our results indicated that when a large number of copepods appear in areas ECS and SCS, C.orsinii may change its relationship with other phytoplanktonic organisms or tend to live in fewer competitors regions to ensure its survival in the coastal ecosystem. It also suggested the latitudinal gradient in an aquatic region could alter planktonic competition and further impact their adaptation [49]. According to PIDA, we found most previous planktonic relationship research focused on the SAR supergroup (i.e., Stramenopiles, Alveolata, and Rhizaria) interaction ( $92 \%$ of total entries), but the connection between copepods, a key organism type in the aquatic food web, and phytoplankton species was rarely investigated. Indicating, that even though the investigation of the relationships between plankton started in 1894 [61], there is still a large knowledge gap about how major planktonic groups are connected. Those results combined with the fact that the interrelationships between many planktonic organisms will change with geographic location, and specific planktonic organisms will be associated with specific species in different regions, were consistent with our second hypothesis that geographic variation could shift planktonic community structure and determine specific planktonic interactions. It indicated there are still many important zooplankton and phytoplankton interactions as yet unexplored in marine ecosystems.

\section{Conclusions}

In the present study, we demonstrated a clear latitudinal pattern in phytoplanktonic and zooplanktonic diversity, geographic distribution, and interactions in Chinese coastal marine ecosystem. The result showed the both zooplanktonic and phytoplanktonic communities were significantly divergent from north to south, in terms of both $\alpha$ - and $\beta$-diversities. Significant distance-decay relationships (DDR) could be observed in both phytoplankton and zooplankton, but the zooplanktonic community had a steeper turnover rate than phytoplankton, indicating heterotrophic zooplankton had more divergent compositions over large distances. Furthermore, the interactions between zooplankton and phytoplankton also exhibited a clear latitudinal pattern, which became more complex from north to south. The particular associations between zooplanktonic and phytoplanktonic species were found in different regions, indicating the latitudinal gradient could restructure the relationships between these two trophically dependent planktons. Our results provide novel insight into large-scale planktonic interactions in coastal marine ecosystems, which is potentially important for understanding how the complex planktonic relationship network responds to the spatial variation under the coastal ecosystem. 


\section{Methods}

\section{Sample collection and physico-chemical analysis}

A total of 251 water samples were collected from 12 sites, which covered the coastal area of China, from the Bohai Sea to the South China Sea. The 12 sites were located from 20 to $40^{\circ} \mathrm{N}$ (Fig. S1) and all samples were collected between August and October 2017. The seawater temperature and precipitation data were obtained from the Met Office Hadley Centre observations datasets and CPC Merged Analysis of Precipitation datasets, respectively. The $\mathrm{pH}$ values were determined with a $\mathrm{pH}$ meter and salinity was measured in situ with a multiparameter sensor YSI6600. $50 \mathrm{~mL}$ of water were collected and stored for analysis of inorganic nutrients $\left(\mathrm{NO}_{3}-\mathrm{N}, \mathrm{NO}_{2}-\mathrm{N}, \mathrm{NH}_{4}-\mathrm{N}\right.$ and $\left.\mathrm{PO}_{4}-\mathrm{P}\right)$ according the method by Grasshoff et al [62]. The Winkler method was used to determine dissolved oxygen (DO). The trophic status of the sampled stations was estimated from values of Chlorophyll-a (using a cascading filtering device to filter 100-200 mL seawater under a low vacuum pressure) and chemical oxygen demand (COD) based on the National Standard of China (GB17378.3-2007). Concentrations of dissolved heavy metals $\left(\mathrm{Cd}^{2+}, \mathrm{Pb}^{2+}\right.$, $\mathrm{Zn}^{2+}$ and $\mathrm{Cu}^{2+}$ ) were analyzed by inductively coupled plasma mass spectrometry and $\mathrm{Hg}^{2+}$ and $\mathrm{As}^{3+}$ were estimated using an atomic fluorescence spectrometer (AFS-920).

\section{Plankton sampling and enumeration}

We measured water depth for each sampling station and used the plankton nets, type $\mathbb{0}(0.160 \mathrm{~mm}$ mesh size, $31.6 \mathrm{~cm}$ mouth diameter) and type $\mathbb{\nabla}(0.077 \mathrm{~mm}$ mesh size, $37 \mathrm{~cm}$ mouth diameter), based on National Standard of China (GB 17678.7-2007), to collect zooplankton and phytoplankton samples, respectively $[63,64]$. Using the vertical tow from $2 \mathrm{~m}$ above the bottom to the surface with the speed of $0.5 \mathrm{~m} / \mathrm{s}$ to collected zooplankton and phytoplankton samples. All samples preserved immediately in $5 \%$ formaldehyde and shipped back to the closest laboratories of National Marine Environmental Monitoring Centers to count and identify the zooplanktonic and phytoplanktonic individuals at the lowest allowable taxonomic level according to the National Standard of China (GBT12763.6-2007) by using microscope $[65,66]$, and according to the database of the World Register of Marine Species (WoRMS, http://www.marinespecies.org/) to check every identified plankton taxonomic names. The density of each planktonic taxa was calculated as the number of individuals divided by the filtered water volume, which was calculated using the rope length multiplied by the mouth area.

\section{Statistical Analysis}

We assessed the alpha diversity of zooplankton and phytoplankton for each sampling sties and three regions. The significance of alpha diversity among locations was tested by Kruskal-Wallis test. Nonmetric multidimensional scaling ordination (NMDS) [67], based on the Sorensen dissimilarity, was used to compare the variance of phytoplanktonic and zooplanktonic community composition in each sampling site. To determine significant differences in planktonic $\beta$-diversity between the different sampling sites, ANOSIM, ADONIS and MRPP were carried out using the 'vegan' package in the R environment [40]. Partial Mantel test was used to identify the relative contributions of geographic distance variables and 
environmental factors to phytoplanktonic and zooplanktonic community dissimilarity. For the spatial variables, we used the Euclidean distance, based on the latitude and longitude coordinates for each pair of sampling stations, as generated by Principal Coordinates of Neighboring Matrices (PCNM) analysis [68]. Environmental factors and PCNM with a variance inflation $<10$ were selected to eliminate collinearity between factors for downstream analyses. The contribution of spatial and environmental factors in shaping planktonic community structure was explained by canonical correlation analysis (CCA) [69]. Variation partitioning analysis (VPA) was conducted to distinguish the contribution of spatial and environmental factors and their combined effect in explaining planktonic community variations [70]. To compare the effects of distance variation on plankton community assembly, we evaluated the distance decay rate for the sampled sites. To reveal the distance-decay rates (DDR) in planktonic communities, Sorensen and geographical distance matrices were compared, and the log geographic distance difference was then plotted against the dissimilarity [71]. All the above analyses were carried out using R software (Version 3.6) [72].

\section{Network analysis and visualization}

To elucidate the interactions between phytoplankton and zooplankton, we constructed an ecological network via the SparCC approaches, which can infer correlation with high accuracy from compositional data, based on IDENAP (http://mem.rcees.ac.cn:8081) workflow [23]. The topological properties (connectance, links per species, specialization asymmetry and web asymmetry) were calculated by IDEN with the aim to show whether the interactions between plankton changed with geographic distance. As in previous studies, the nodes were divided into four groups: peripheral nodes $\left(Z_{i} \leq 2.5\right.$ and $\left.P_{i} \leq 0.62\right)$, connectors $\left(Z_{i} \leq 2.5\right.$ and $\left.P_{i}>0.62\right)$, network hubs $\left(Z_{i}>2.5\right.$ and $\left.P_{i}>0.62\right)$ and module hubs $\left(Z_{i}>2.5\right.$ and $\left.P_{i} \leq 0.62\right)$ [73]. The obtained network was visualized in Gephi (0.9.1) [74] and Cytoscape [75].

\section{Declarations}

\section{Acknowledgements}

We gratefully thank Dr. James W. Voordeckers for his suggestions and grammar corrections on this paper.

\section{Authors' contributions}

All authors contributed the intellectual input and assistance to this study and manuscript preparation. YD developed the original research plan. $\mathrm{HL}$ implemented sampling; ZZ did data analysis and created the figures; ZZ with help YD wrote the paper. All authors have reviewed and agreed with the paper.

\section{Funding}

This work was financially supported by the National Science Foundation of China (No. 91851106; 31861133002); the Key Research Program of Frontier Sciences, CAS (QYZDB-SSW-DQC026). 
Availability of data and materials

The zooplanktonic and phytoplanktonic species tables are available from our own webpage http://mem.rcees.ac.cn/download.html.

\section{Ethics approval and consent to participate}

Not applicable.

\section{Consent for publication}

Not applicable.

\section{Competing interests}

The authors declare that they have no conflict of interest.

\section{References}

1. Pierella Karlusich, JJ; Ibarbalz, FM; Bowler, C Phytoplankton in the Tara Ocean. Annual Review of Marine Science. 2020;12(1):233-265.

2. Mitra, A; Flynn, KJ; Tillmann, U; Raven, JA; Caron, D; Stoecker, DK, et al. Defining Planktonic Protist Functional Groups on Mechanisms for Energy and Nutrient Acquisition: Incorporation of Diverse Mixotrophic Strategies. Protist. 2016;167(2):106-20.

3. Batten, SD; Abu-Alhaija, R; Chiba, S; Edwards, M; Graham, G; Jyothibabu, R, et al. A Global Plankton Diversity Monitoring Program. Frontiers in Marine Science. 2019;6.

4. Hays, GC; Richardson, AJ; Robinson, C Climate change and marine plankton. Trends Ecol Evol. 2005;20(6):337-44.

5. Capo, E; Debroas, D; Arnaud, F; Perga, ME; Chardon, C; Domaizon, I Tracking a century of changes in microbial eukaryotic diversity in lakes driven by nutrient enrichment and climate warming. Environ Microbiol. 2017;19(7):2873-2892.

6. Serra-Pompei, C; Hagstrom, Gl; Visser, AW; Andersen, KH Resource limitation determines temperature response of unicellular plankton communities. Limnology and Oceanography. 2019;64(4):16271640.

7. Filker, S; Forster, D; Weinisch, L; Mora-Ruiz, M; Gonzalez, B; Farias, ME, et al. Transition boundaries for protistan species turnover in hypersaline waters of different biogeographic regions. Environ Microbiol. 2017;19(8):3186-3200.

8. Haruko Kurihara; Shinji Shimode; Shirayama, Y Sub-Lethal Effects of Elevated Concentration of CO2 on Planktonic Copepods and Sea Urchins. Journal of Oceanography. 2004;60:743-750.

9. Falkowski, PG; Oliver, MJ Mix and match how climate selects phytoplankton. Nature Reviews Microbiology 2007;5:813-819. 
10. Caron, DA; Hutchins, DA The effects of changing climate on microzooplankton grazing and community structure: drivers, predictions and knowledge gaps. Journal of Plankton Research. 2013;35(2):235-252.

11. Shade, A; Dunn, RR; Blowes, SA; Keil, P; Bohannan, BJM; Herrmann, M, et al. Macroecology to Unite All Life, Large and Small. Trends Ecol Evol. 2018;33(10):731-744.

12. Bjorbaekmo, MFM; Evenstad, A; Rosaeg, LL; Krabberod, AK; Logares, R The planktonic protist interactome: where do we stand after a century of research? ISME J. 2020;14(2):544-559.

13. Zinger, L; Boetius, A; Ramette, A Bacterial taxa-area and distance-decay relationships in marine environments. Mol Ecol. 2014;23(4):954-64.

14. Soininen, J; McDonald, R; Hillebrand, $\mathrm{H}$ The distance decay of similarity in ecological communities. Ecography. 2007;30(1):3-12.

15. Dumbrell, AJ; Nelson, M; Helgason, T; Dytham, C; Fitter, AH Erratum: Relative roles of niche and neutral processes in structuring a soil microbial community. The ISME Journal. 2010;4(8):1078-1078.

16. Chase, JM Stochastic community assembly causes higher biodiversity in more productive environments. Science. 2010;328(5984):1388-91.

17. Worden, AZ; Follows, MJ; Giovannoni, SJ; Wilken, S; Zimmerman, AE; Keeling, PJ Rethinking the marine carbon cycle: factoring in the multifarious lifestyles of microbes. Science. 2015;347(6223):1257594.

18. Berry, D; Widder, S Deciphering microbial interactions and detecting keystone species with cooccurrence networks. Front Microbiol. 2014;5:219.

19. Faust, K; Raes, J Microbial interactions: from networks to models. Nat Rev Microbiol. 2012;10(8):53850.

20. Coyte, KZ; Schluter, J; Foster, KR The ecology of the microbiome: Networks, competition, and stability. Science. 2015;350:4.

21. Layeghifard, M; Hwang, DM; Guttman, DS Disentangling Interactions in the Microbiome: A Network Perspective. Trends Microbiol. 2017;25(3):217-228.

22. Thebault, E; Fontaine, C Stability of ecological communities and the architecture of mutualistic and trophic networks. Science. 2010;329(5993):853-6.

23. Feng, K; Zhang, Y; He, Z; Ning, D; Deng, Y Interdomain ecological networks between plants and microbes. Mol Ecol Resour. 2019;19(6):1565-1577.

24. Zhou, J; Deng, Y; Luo, F; He, Z; Yang, Y Phylogenetic molecular ecological network of soil microbial communities in response to elevated CO2. mBio. 2011;2(4).

25. Harley, CDG; Randall Hughes, A; Hultgren, KM; Miner, BG; Sorte, CJB; Thornber, CS, et al. The impacts of climate change in coastal marine systems. Ecology Letters. 2006;9(2):228-241.

26. Taylor, AH; Allen, Jl; Clark, PA Extraction of a weak climaticsignal by an ecosystem. Nature. 2002;416:629-632. 
27. Mahe, F; de Vargas, C; Bass, D; Czech, L; Stamatakis, A; Lara, E, et al. Parasites dominate hyperdiverse soil protist communities in Neotropical rainforests. Nat Ecol Evol. 2017;1(4):91.

28. Biard, T; Stemmann, L; Picheral, M; Mayot, N; Vandromme, $\mathrm{P}$; Hauss, $\mathrm{H}$, et al. In situ imaging reveals the biomass of giant protists in the global ocean. Nature. 2016;532(7600):504-7.

29. Ibarbalz, FM; Henry, N; Brandao, MC; Martini, S; Busseni, G; Byrne, H, et al. Global Trends in Marine Plankton Diversity across Kingdoms of Life. Cell. 2019;179(5):1084-1097 e21.

30. Fuhrman, JA; Steele, JA; Hewson, I; Schwalbach, MS; Brown, MV; Green, JL, et al. A latitudinal diversity gradient in planktonicmarine bacteria. Proceedings of the National Academy of Sciences. 2008;105(22):7774-7778.

31. Acevedo-Trejos, E; Maranon, E; Merico, A Phytoplankton size diversity and ecosystem function relationships across oceanic regions. Proc Biol Sci. 2018;285(1879).

32. Nakano, S-i; Ishii, N; Manage, PM; Kawabata, Zi Trophic roles of heterotrophic nanoflagellates and ciliates among planktonic organisms in a hypereutrophic pond. Aquatic Microbial Ecology 1998;161:153-161.

33. Lepere, C; Boucher, D; Jardillier, L; Domaizon, I; Debroas, D Succession and regulation factors of small eukaryote community composition in a lacustrine ecosystem (Lake Pavin). Appl Environ Microbiol. 2006;72(4):2971-81.

34. Chen, MJ; Chen, FZ; Xing, P; Li, HB; Wu, QLL Microbial eukaryotic community in response to Microcystis spp. bloom, as assessed by an enclosure experiment in Lake Taihu, China. FEMS Microbiol Ecol. 2010;74(1):19-31.

35. Wang, Y; Liu, L; Chen, $\mathrm{H}$; Yang, J Spatiotemporal dynamics and determinants of planktonic bacterial and microeukaryotic communities in a Chinese subtropical river. Applied Microbiology and Biotechnology. 2015;99(21):9255-9266.

36. Logares, R; Lindstrom, ES; Langenheder, S; Logue, JB; Paterson, H; Laybourn-Parry, J, et al. Biogeography of bacterial communities exposed to progressive long-term environmental change. ISME J. 2013;7(5):937-48.

37. Yeh, YC; Peres-Neto, PR; Huang, SW; Lai, YC; Tu, CY; Shiah, FK, et al. Determinism of bacterial metacommunity dynamics in the southern East China Sea varies depending on hydrography. Ecography. 2015;38(2):198-212.

38. Barton, PS; Cunningham, SA; Manning, AD; Gibb, H; Lindenmayer, DB; Didham, RK The spatial scaling of beta diversity. Global Ecology and Biogeography. 2013;22(6):639-647.

39. Morlon, H; Chuyong, G; Condit, R; Hubbell, S; Kenfack, D; Thomas, D, et al. A general framework for the distance-decay of similarity in ecological communities. Ecol Lett. 2008;11(9):904-17.

40. Wang, XH; Wen, X; Deng, Y; Xia, Y; Yang, YF; Zhou, JZ Distance-Decay Relationship for Biological Wastewater Treatment Plants. Appl Environ Microbiol. 2016;82(16):4860-6.

41. Nekola, JC; White, PS The distance decay of similarity in biogeography and ecology. Journal of Biogeography. 1999;26(4):867-878. 
42. Guidi, L; Chaffron, S; Bittner, L; Eveillard, D; Larhlimi, A; Roux, S, et al. Plankton networks driving carbon export in the oligotrophic ocean. Nature. 2016;532(7600):465-470.

43. Chow, CE; Kim, DY; Sachdeva, R; Caron, DA; Fuhrman, JA Top-down controls on bacterial community structure: microbial network analysis of bacteria, T4-like viruses and protists. ISME J. 2014;8(4):81629.

44. Hu, Q; Tan, L; Gu, S; Xiao, Y; Xiong, X; Zeng, WA, et al. Network analysis infers the wilt pathogen invasion associated with non-detrimental bacteria. NPJ Biofilms Microbiomes. 2020;6(1):8.

45. Deng, Y; Zhang, P; Qin, Y; Tu, Q; Yang, Y; He, Z, et al. Network succession reveals the importance of competition in response to emulsified vegetable oil amendment for uranium bioremediation. Environ Microbiol. 2016;18(1):205-18.

46. Wang, Y; Zhang, R; Zheng, Q; Deng, Y; Van Nostrand, JD; Zhou, J, et al. Bacterioplankton community resilience to ocean acidification: evidence from microbial network analysis. ICES Journal of Marine Science. 2016;73(3):865-875.

47. Li, W; Xu, X; Yao, J; Tanaka, N; Nishimura, O; Ma, H Combined effects of elevated carbon dioxide and temperature on phytoplankton-zooplankton link: A multi-influence of climate change on freshwater planktonic communities. Sci Total Environ. 2019;658:1175-1185.

48. Behrenfeld, MJ Climate-mediated dance of the plankton. Nature Climate Change. 2014;4(10):880887.

49. Thomas, MK; Kremer, CT; Klausmeier, CA; Litchman, E A global pattern of thermal adaptation in marine phytoplankton. Science. 2012;338(6110):1085-8.

50. Hopkinson, BM; Dupont, CL; Allen, AE; Morel, FM Efficiency of the CO2-concentrating mechanism of diatoms. Proc Natl Acad Sci U S A. 2011;108(10):3830-7.

51. Malviya, S; Scalco, E; Audic, S; Vincent, F; Veluchamy, A; Poulain, J, et al. Insights into global diatom distribution and diversity in the world's ocean. Proc Natl Acad Sci U S A. 2016;113(11):E1516-25.

52. Rombouts, I; Beaugrand, G; Ibanez, F; Gasparini, S; Chiba, S; Legendre, L Global latitudinal variations in marine copepod diversity and environmental factors. Proc Biol Sci. 2009;276(1670):3053-62.

53. Okie, JG; Van Horn, DJ; Storch, D; Barrett, JE; Gooseff, MN; Kopsova, L, et al. Niche and metabolic principles explain patterns of diversity and distribution: theory and a case study with soil bacterial communities. Proc Biol Sci. 2015;282(1809):20142630.

54. Chen, ZY; Lundholm, N; Moestrup, O; Kownacka, J; Li, Y Chaetoceros pauciramosus sp. nov. (Bacillariophyceae), a Widely Distributed Brackish Water Species in the C. Iorenzianus Complex. Protist. 2018;169(5):615-631.

55. Kownacka, J; Edler, L; Gromisz, S; Łotocka, M; Olenina, I; Ostrowska, M, et al. Non-indigenous species Chaetoceros cf. Iorenzianus Grunow 1863 - A new, predominant component of autumn phytoplankton in the southern Baltic Sea. Estuarine, Coastal and Shelf Science. 2013;119:101-111.

56. Baek, SH; Shimode, S; Han, MS; Kikuchi, T Growth of dinoflagellates, Ceratium furca and Ceratium fusus in Sagami Bay, Japan: The role of nutrients. Harmful Algae. 2008;7(6):729-739. 
57. Percec, V; Glodde, M; Bera, TK; Miura, Y; Shiyanovskaya, l; Singer, KD, et al. Self-organization of supramolecular helical dendrimers into complex electronic materials. Nature. 2002;419(6905):384-7.

58. Koski, M; Boutorh, J; de la Rocha, C Feeding on dispersed vs. aggregated particles: The effect of zooplankton feeding behavior on vertical flux. PLoS One. 2017;12(5):e0177958.

59. Calvo, E; Simó, R; Coma, R; Ribes, M; Pascual, J; Sabatés, A, et al. Effects of climate change on Mediterranean marine ecosystems: the case of the Catalan Sea. Climate Research. 2011;50(1):1-29.

60. Blanco-Bercial, L; Bucklin, A New view of population genetics of zooplankton: RAD-seq analysis reveals population structure of the North Atlantic planktonic copepod Centropages typicus. Mol Ecol. 2016;25(7):1566-80.

61. Koeppen, N Amoebophrya stycholonchae nov. gen. et sp. (corps spiral de Fol). Zoologischer Anzeiger. 1894;17.

62. Grasshoff, K; Kremling, K; Ehrhardt, M Methods of Seawater Analysis, 3rd Edition. Wiley-VCH区 New York. 2007.

63. Hwang, JS; Kumar, R; Dahms, HU; Tseng, LC; Chao, Q Mesh Size Affects Abundance Estimates of Oithona spp. (Copepoda, Cyclopoida). Crustaceana. 2007;80:827-837.

64. Riccardi, N Selectivity of plankton nets over mesozooplankton taxa implications for abundance, biomass and diversity estimation. Journal of limnology. 2010;69:287-296.

65. Zheng, Z; Li, S; Xu, Z Marine Planktology. China Ocean Press \& Spring Verlag. 1989.

66. Sun, s; Li, c; Cheng, $f ;$ Jin, $x ;$ Yang, b Atlas of Common Zooplanton of the Chinese Coastal Seas. China Ocean press. 2015.

67. Palmer, C; Bik, EM; DiGiulio, DB; Relman, DA; Brown, PO Development of the Human Infant IntestinalMicrobiota. Plos Biology. 2007;https://doi.org/10.1371/journal.pbio.0050177.

68. Legendre, P Studying beta diversity: ecological variation partitioning by multiple regression and canonical analysis. Journal of Plant Ecology. 2007;1 (1):3-8.

69. Smilauer, P; Lep`s, J Multivariate Analysis of Ecological Data using Canoco 5. 2014.

70. Pedro R, P-N; Pierre, L; Stéphane, D; Daniel, B Variation partitioning of species data matrices: estimation and comparison of fractions. Ecology. 2006;87(10):2614-2625.

71. Oono, R; Rasmussen, A; Lefèvre, E Distance decay relationships in foliar fungal endophytes are driven by rare taxa. Environmental Microbiology. 2017;19(7):2794-2805.

72. Bedford, J; Johns, D; McQuatters-Gollop, A; Thurstan, R A century of change in North Sea plankton communities explored through integrating historical datasets. ICES Journal of Marine Science. 2019;76(1):104-112.

73. Deng, Y; Jiang, YH; Yang, YF; He, ZL; Luo, F; Zhou, JZ Molecular ecological network analyses. BMC Bioinformatics. 2012;13(113).

74. Bastian, M; Heymann, S; Jacomy, M Gephi: An open source software for exploring and manipulating networks: International AAAl conference on web and social media. 2009. 
75. Shannon, P; Markiel, A; Ozier, O; Baliga, NS; Wang, JT; Ramage, D, et al. Cytoscape: a software environment for integrated models of biomolecular interaction networks. Genome Res. 2003;13(11):2498-504.

\section{Figures}

A

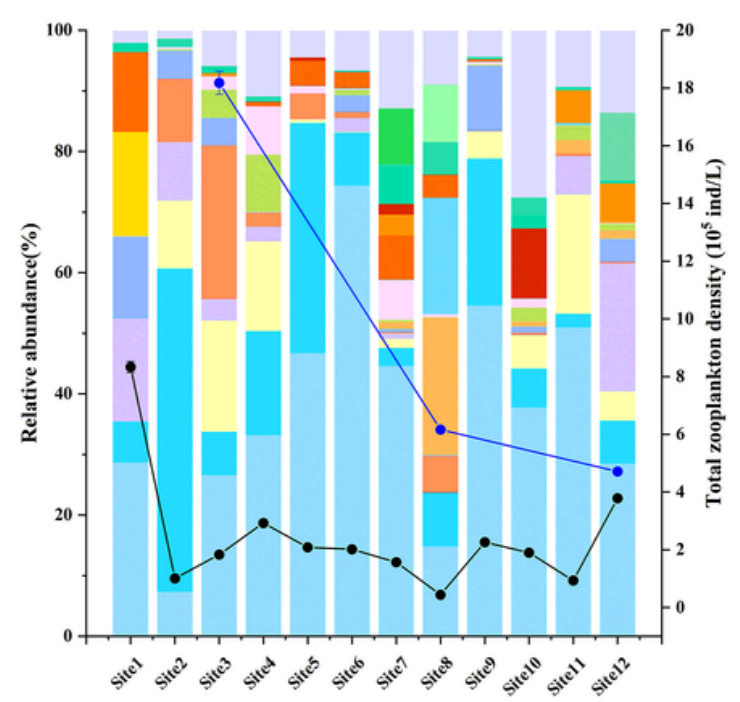

B

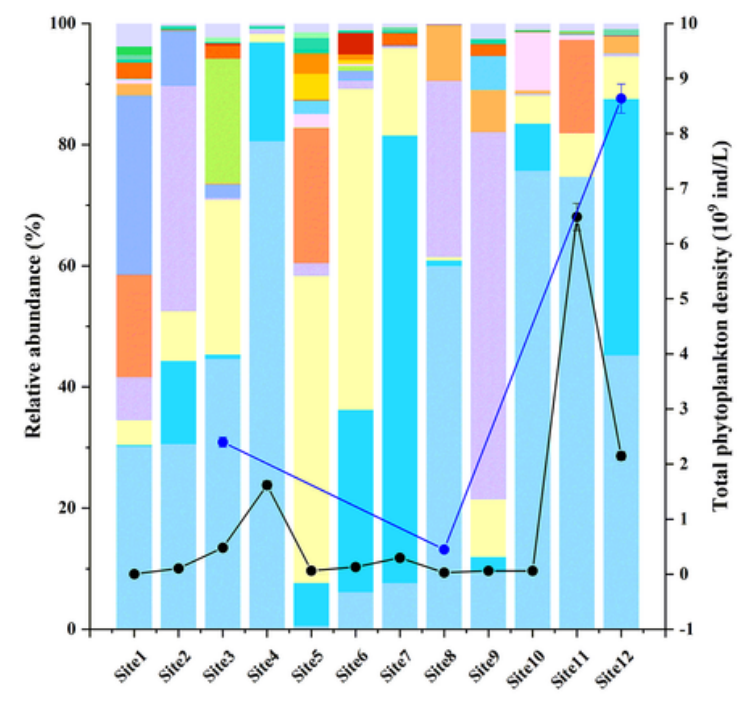

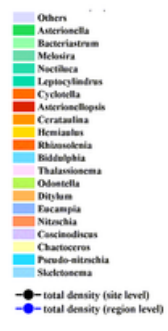

Figure 1

Histogram and line chart showing the relative abundance of top 20 genera and total planktonic density. (A) zooplankton, (B) phytoplankton. The sampling sites divided into three geographic regions, the Bohai Sea (BS), the East China Sea (ECS), and the South China Sea (SCS). The black line and blue line illustrated the total planktonic density at site level and region level respectively.

A

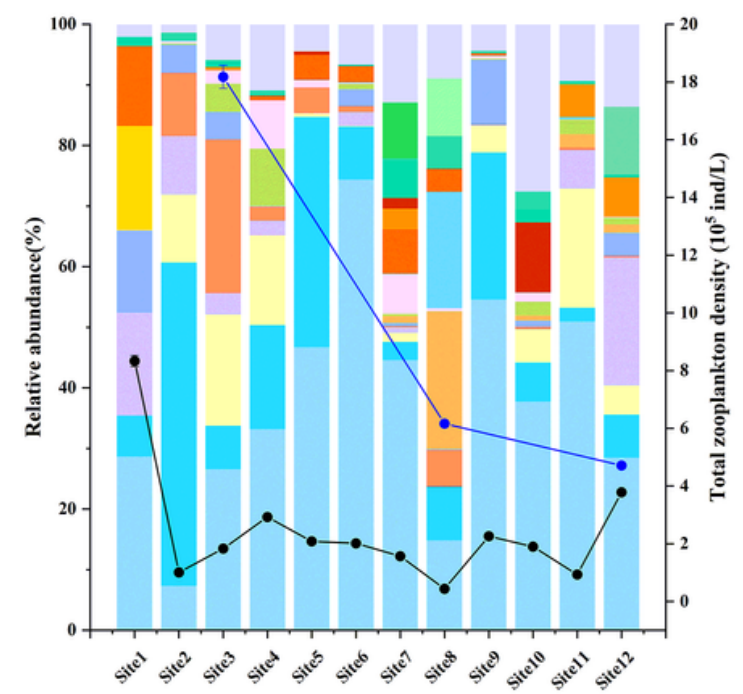

B

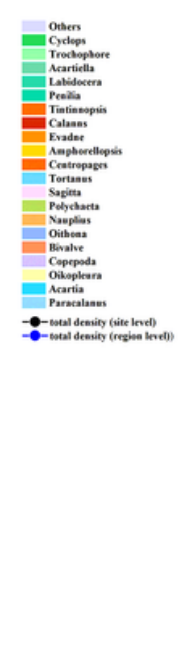

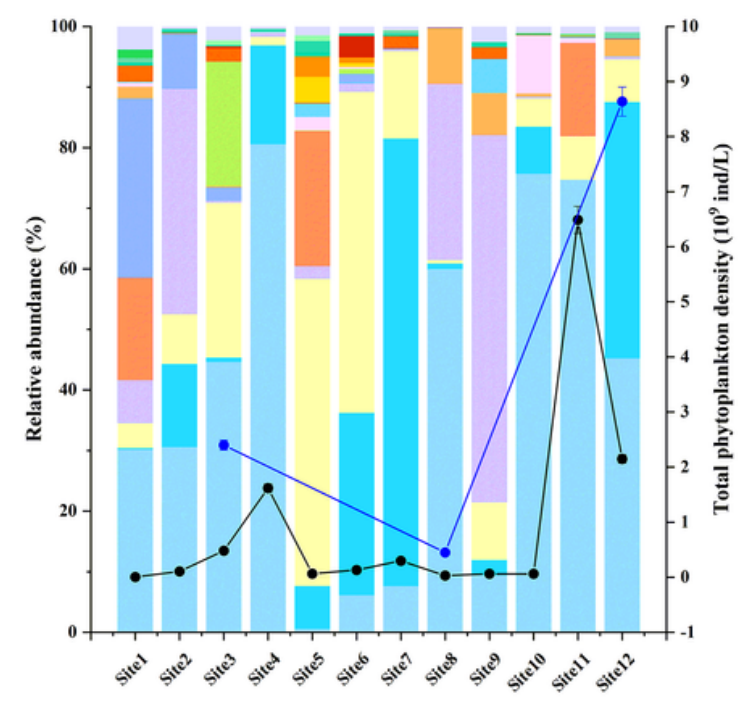

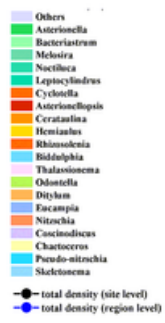


Figure 1

Histogram and line chart showing the relative abundance of top 20 genera and total planktonic density. (A) zooplankton, (B) phytoplankton. The sampling sites divided into three geographic regions, the Bohai Sea (BS), the East China Sea (ECS), and the South China Sea (SCS). The black line and blue line illustrated the total planktonic density at site level and region level respectively.

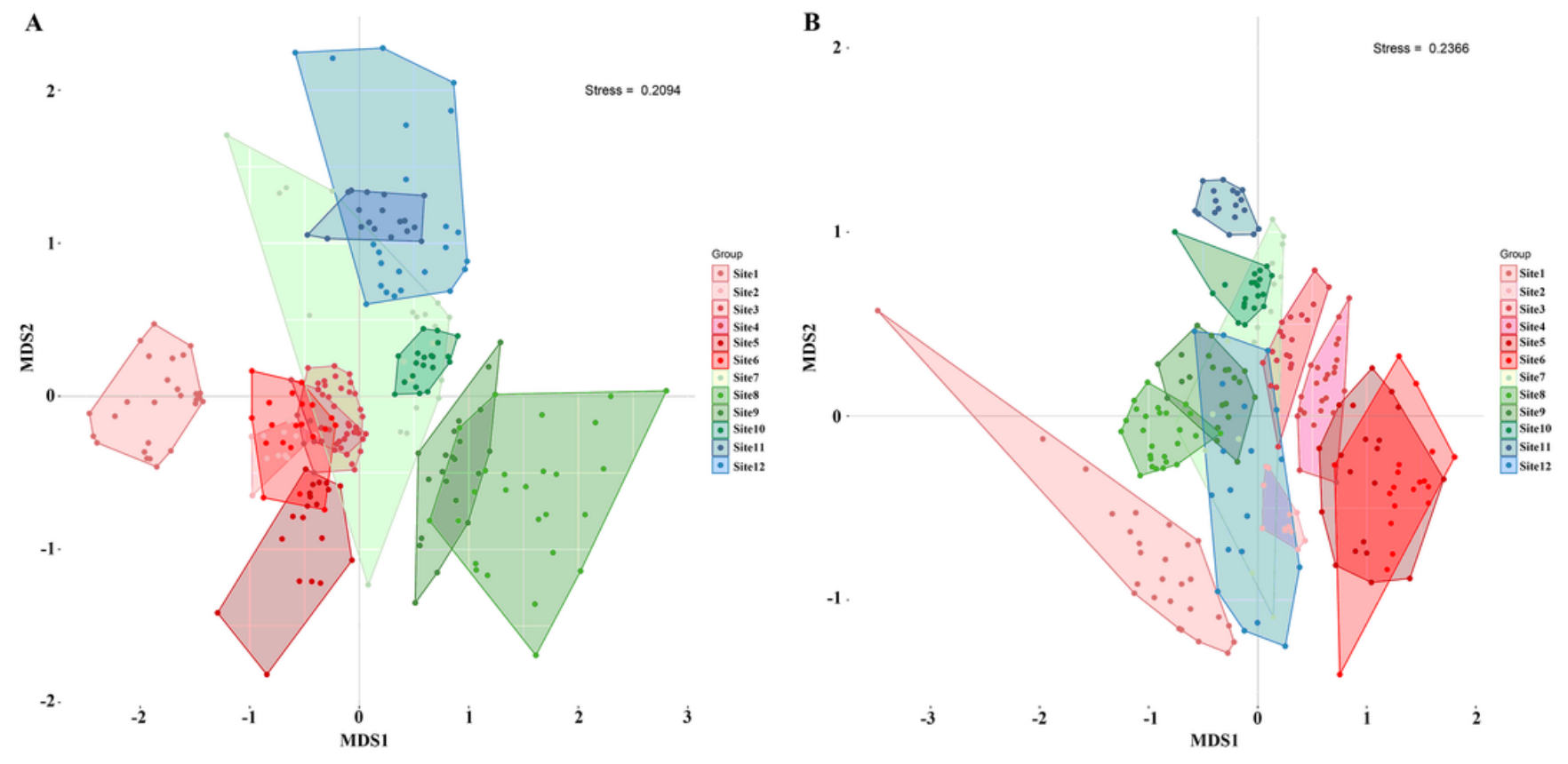

\section{Figure 2}

Distributions of zooplankton and phytoplankton across 12 sampling sites. Non-metric multidimensional scaling (NMDS) based on the Sorensen distances of zooplankton (A) and phytoplankton (B) communities across all sampling sites. All points are colored according to 12 sampling sites. 


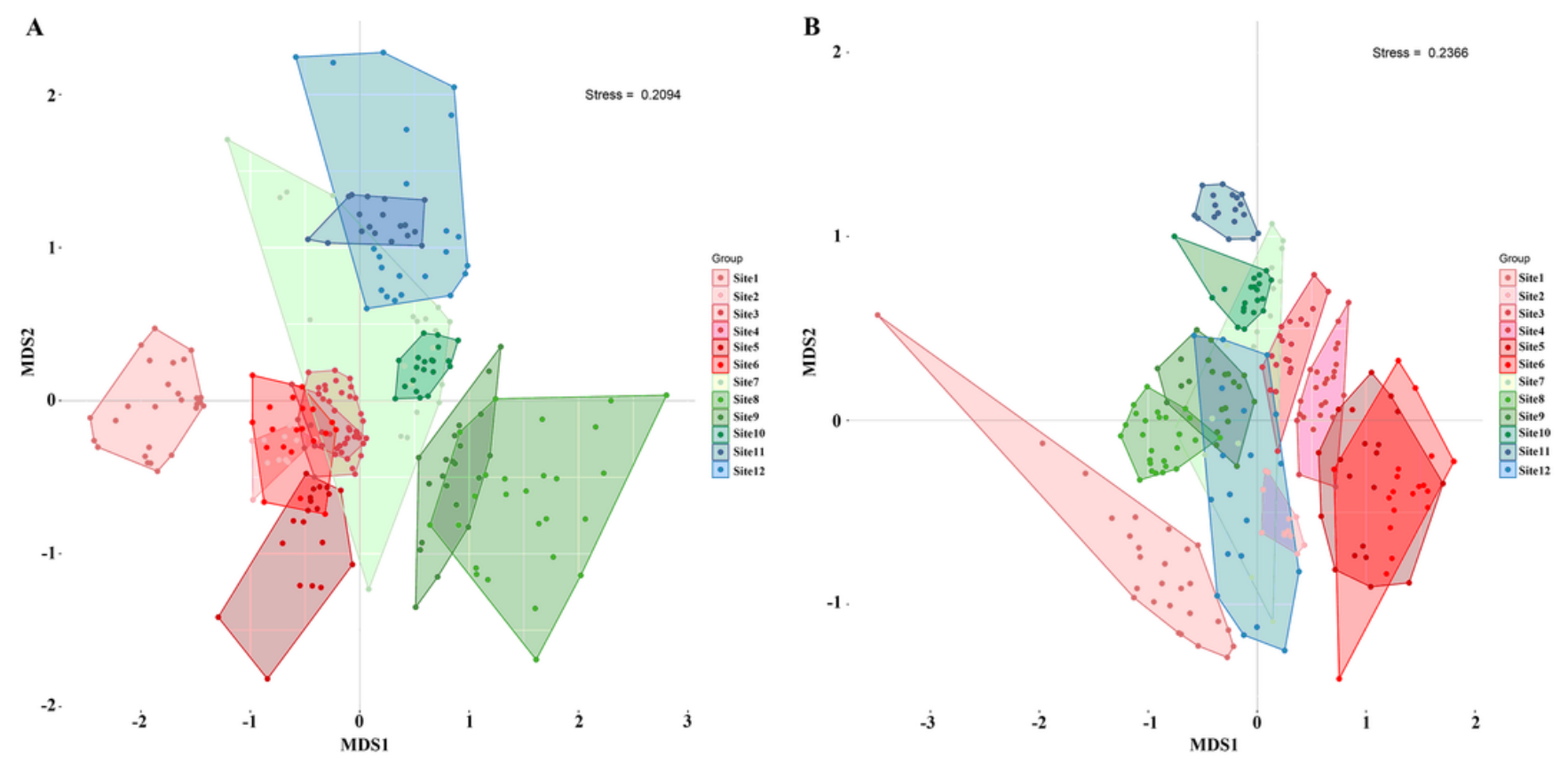

Figure 2

Distributions of zooplankton and phytoplankton across 12 sampling sites. Non-metric multidimensional scaling (NMDS) based on the Sorensen distances of zooplankton (A) and phytoplankton (B) communities across all sampling sites. All points are colored according to 12 sampling sites. 
A

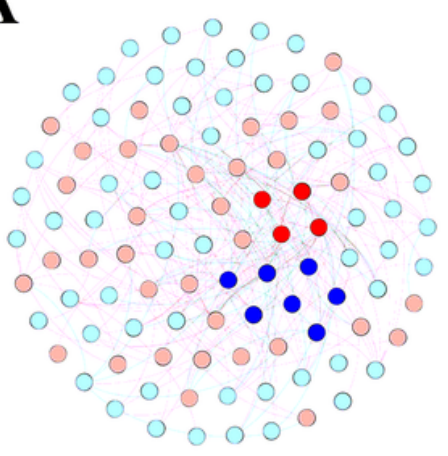

D

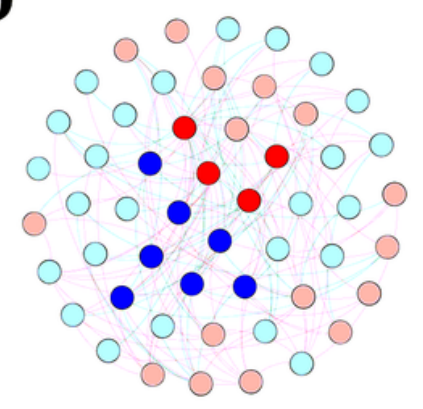

G

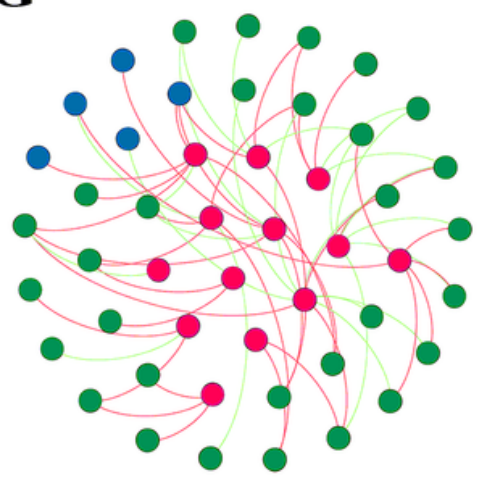

B

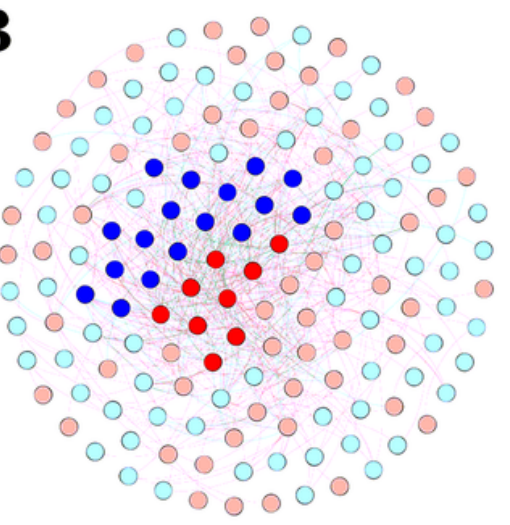

E

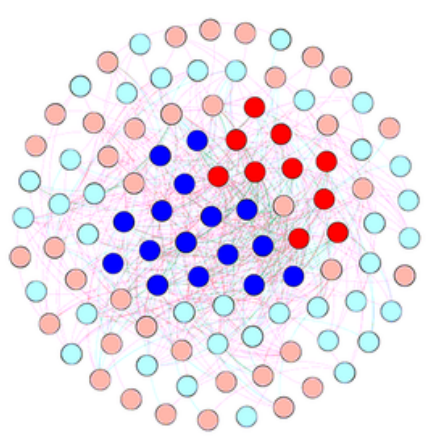

H

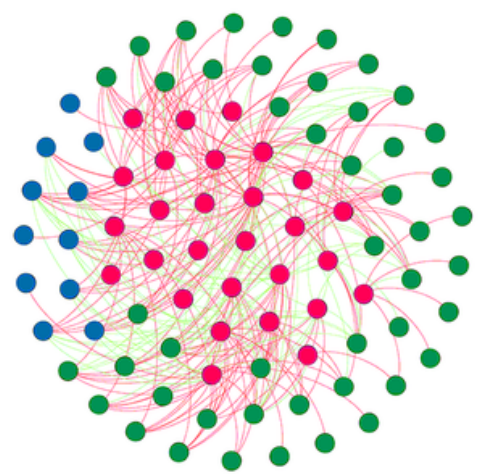

C

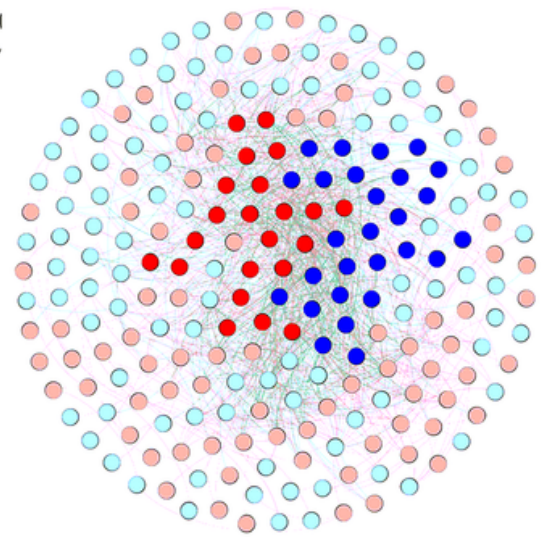

F

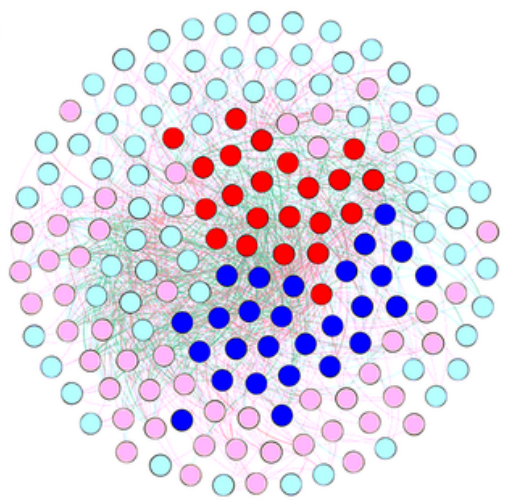

I

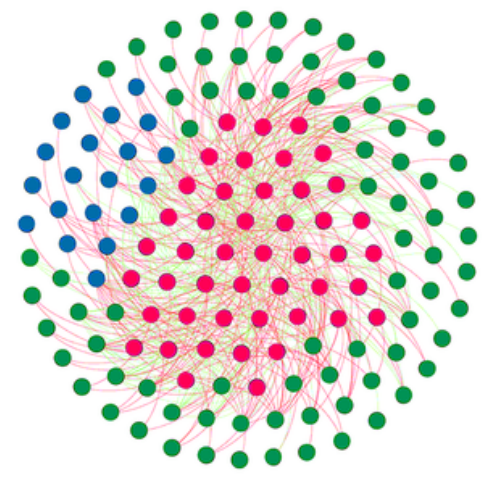

Zooplankton

Phytoplankton keystone Z Tooplakton keystones Diatom Dinoflagellates

Figure 3

The network of phytoplankton and zooplankton interaction (A-F), and the subnetwork for the interactions among three predominant planktonic groups (copepods, diatoms, and dinoflagellates) were extracted from plankton keystones subnetworks $(\mathrm{G}-\mathrm{I})$. Light red nodes represent zooplankton. Light blue nodes represent phytoplankton. Dark blue nodes represent phytoplankton keystone taxa. Dark red nodes represent zooplankton keystone taxa. In subnetwork, the nodes were colored according to different planktonic group. Lines connecting nodes (edges) represented positive (red) and negative (green) 
interactions. The top panels $(A, B, C)$ show the network of phytoplanktonic and zooplanktonic communities. The middle panels (D, E, F) show the keystone taxa subnetwork. The bottom panels $(G, H, I)$ show the three predominant planktonic groups subnetwork. (A, D, G) The network of planktonic communities among BS sites. (B, E, H) Network of planktonic communities among ECS sites. $(C, F, I)$ Network of planktonic communities among SCS sites.

A

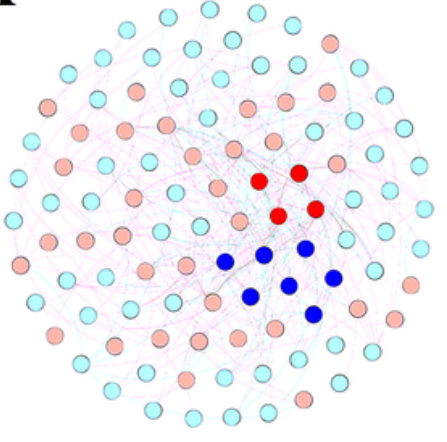

D

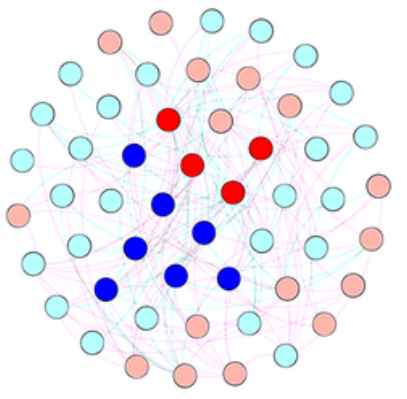

G

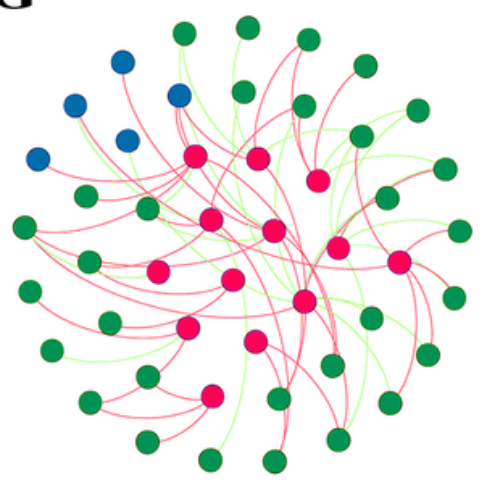

B

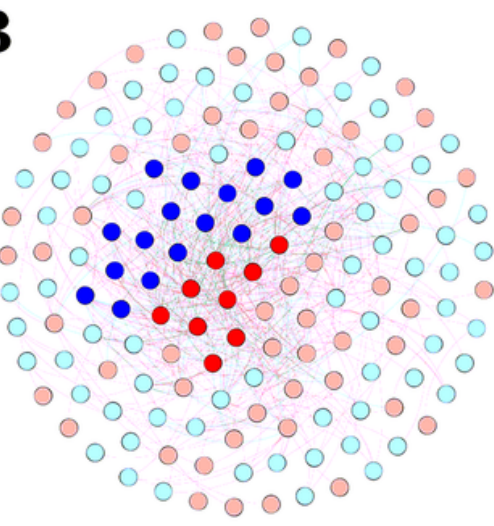

$\mathbf{E}$

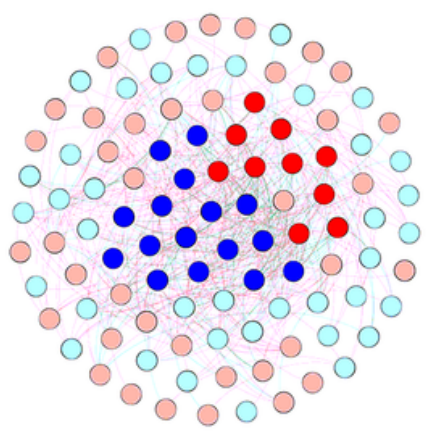

H

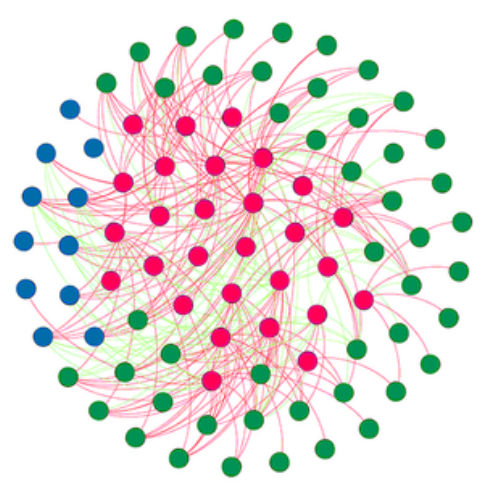

C

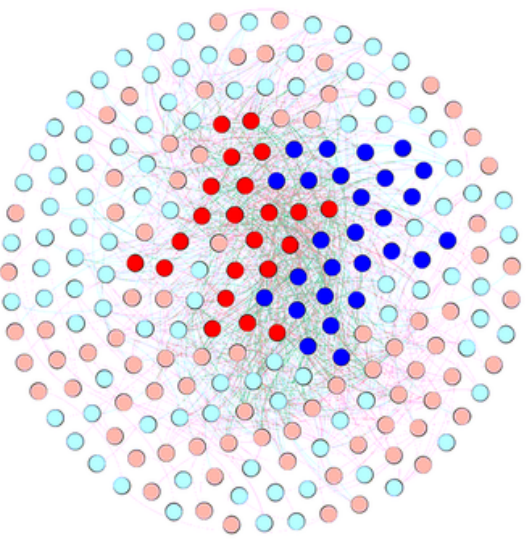

F

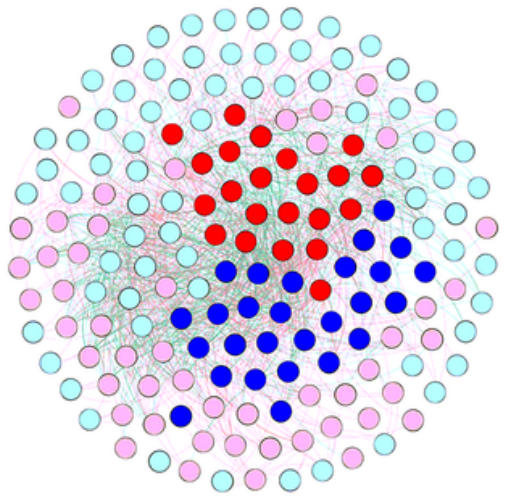

I

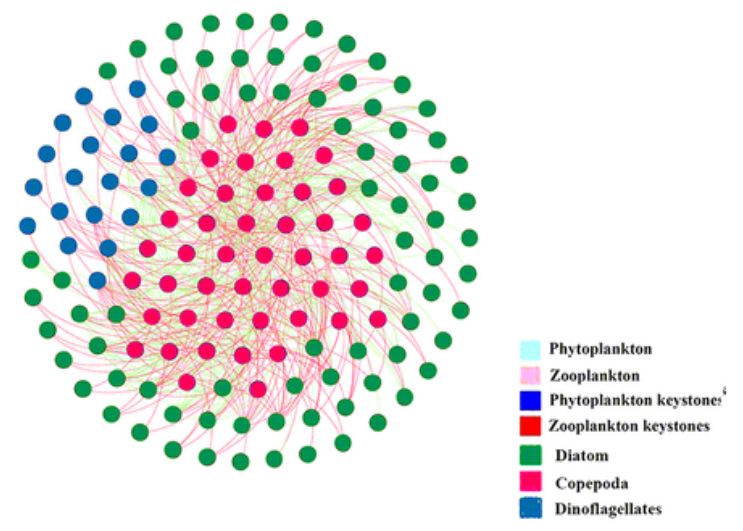

Figure 3 
The network of phytoplankton and zooplankton interaction $(A-F)$, and the subnetwork for the interactions among three predominant planktonic groups (copepods, diatoms, and dinoflagellates) were extracted from plankton keystones subnetworks $(\mathrm{G}-\mathrm{I})$. Light red nodes represent zooplankton. Light blue nodes represent phytoplankton. Dark blue nodes represent phytoplankton keystone taxa. Dark red nodes represent zooplankton keystone taxa. In subnetwork, the nodes were colored according to different planktonic group. Lines connecting nodes (edges) represented positive (red) and negative (green) interactions. The top panels (A, B, C) show the network of phytoplanktonic and zooplanktonic communities. The middle panels $(D, E, F)$ show the keystone taxa subnetwork. The bottom panels $(G, H, I)$ show the three predominant planktonic groups subnetwork. (A, D, G) The network of planktonic communities among BS sites. (B, E, H) Network of planktonic communities among ECS sites. $(C, F, I)$ Network of planktonic communities among SCS sites.

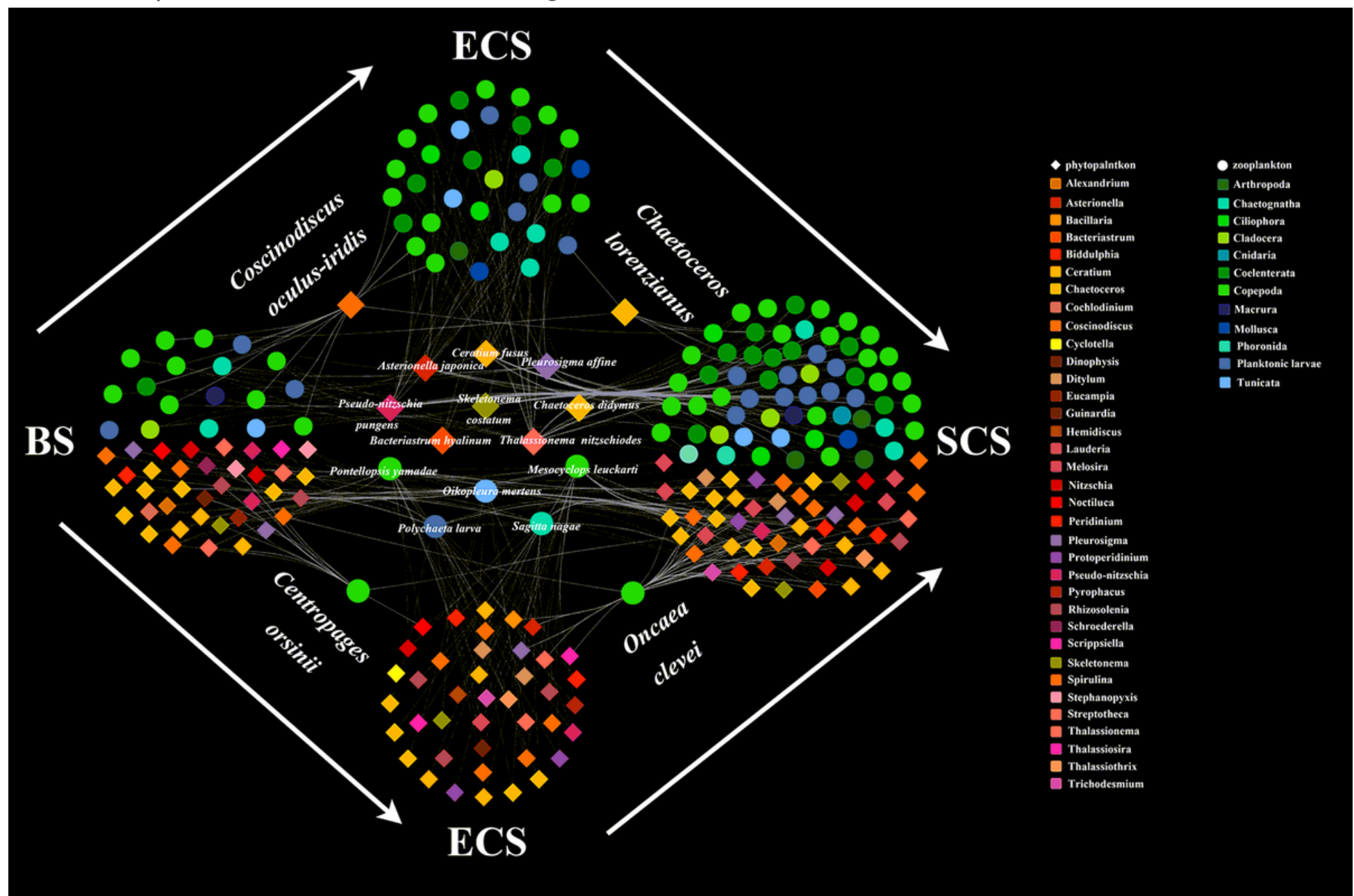

Figure 4

The network of interactions between the common planktonic species and other planktonic organisms in the three sampling regions. Circular nodes represent zooplanktonic species, Rhombus nodes represent phytoplanktonic species and lines connecting nodes (edges) represented a statistically significant association between nodes. Blue lines mean that the number of links was highest in the BS region, while red lines mean that the highest link number was observed in the SCS. The arrows represent the latitude decreases. 


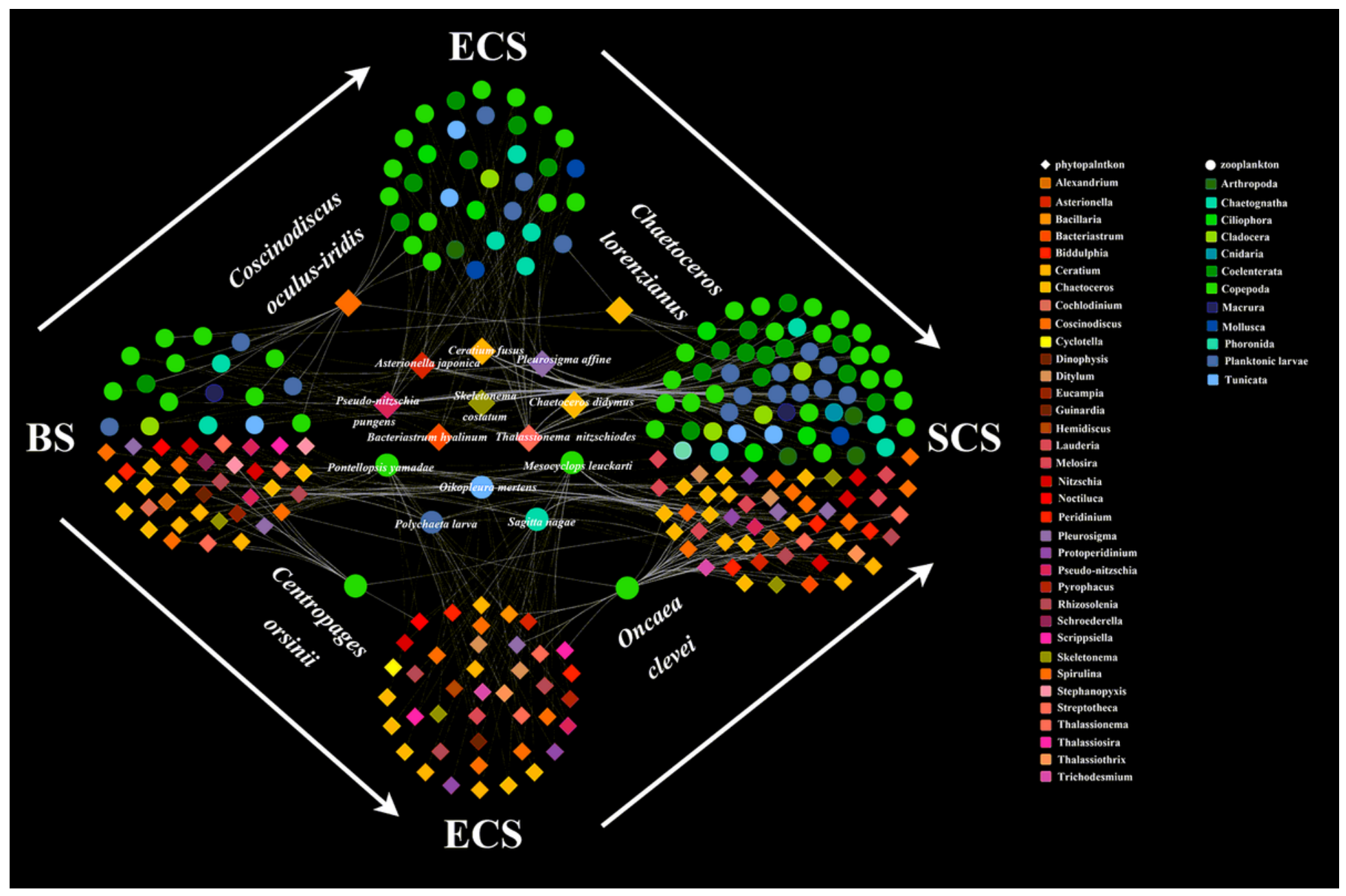

\section{Figure 4}

The network of interactions between the common planktonic species and other planktonic organisms in the three sampling regions. Circular nodes represent zooplanktonic species, Rhombus nodes represent phytoplanktonic species and lines connecting nodes (edges) represented a statistically significant association between nodes. Blue lines mean that the number of links was highest in the BS region, while red lines mean that the highest link number was observed in the SCS. The arrows represent the latitude decreases.

\section{Supplementary Files}

This is a list of supplementary files associated with this preprint. Click to download.

- Supplementalfile.docx

- Supplementalfile.docx 